\title{
Association between Cardiac Outcomes and Indoxyl Sulfate Levels in Hemodialysis Patients: A Cross-Sectional Study
}

\author{
Zhuo Li $^{\mathrm{a}}$ Guibao Ke ${ }^{\mathrm{b}}$ Li Song $^{\mathrm{a}}$ Junlin Huang ${ }^{\mathrm{c}}$ Yamei Zhang $^{\mathrm{d}}$ Jie Xiao $^{\mathrm{b}}$ \\ Shuangxin Liu ${ }^{\mathrm{a}}$ Xinling Liang ${ }^{\mathrm{a}}$ \\ aDepartment of Nephrology, Guangdong Provincial People's Hospital, Guangdong Academy of Medical \\ Sciences, Guangzhou, PR China; ${ }^{\text {b}}$ Department of Nephrology, The First Affiliated Hospital of Guangzhou Medical \\ University, Guangzhou Medical University, Guangzhou, PR China; 'Department of Cardiology, Guangdong \\ Cardiovascular Institute, Guangdong Provincial People's Hospital, Guangdong Academy of Medical Sciences, \\ Guangzhou, PR China; dSichuan Medicine Key Laboratory of Clinical Genetics, Affiliated Hospital \& Clinical Medical \\ College of Chengdu University, Chengdu, PR China
}

\section{Keywords}

Indoxyl sulfate $\cdot$ Cardiac outcomes $\cdot$ Hemodialysis

\begin{abstract}
Objective: Indoxyl sulfate (IS) is a protein-bound uremic toxin that is associated with cardiovascular events and mortality in hemodialysis (HD) patients. However, the factors affecting the levels of IS are currently unclear. This study aimed to investigate the factors influencing serum IS concentrations in HD patients. Methods: We included 100 HD patients from Guangdong Provincial People's Hospital. Baseline characteristics, including sex, age, clinical features, duration of $H D$, echocardiography findings, electrocardiogram results, and biochemical indicators, were collected and analyzed in relation to serum total-form IS levels. Results: Among all 100 patients, serum IS levels were significantly higher in patients aged $\geq 60$ years, males, and patients with mitral regurgitation and inadequate dialysis. Among patients aged $<60$ years, IS levels were significantly higher among patients with mitral regurgitation compared with those without. Furthermore, multiple linear regression analysis identified sex, age,
\end{abstract}

ventricular septal thickness, and mitral regurgitation as factors independently associated with serum IS (STD $\beta=-0.475$, $0.162,-0.153,0.142$, and 0.136 , respectively; all $p<0.05$ ) adjusted for body mass index, smoking, and fasting plasma glucose. Conclusions: Male sex, age $\geq 60$ years, ventricular septal thickness, and mitral regurgitation are factors associated with high total serum IS concentrations in Chinese HD patients. Elevated IS levels may play a role in the process of mitral regurgitation in HD patients $<60$ years of age.

\footnotetext{
(C) 2021 The Author(s).

Published by S. Karger AG, Basel
}

\section{Introduction}

The results of the China Chronic Kidney Disease Epidemiological Survey in 2012 showed a prevalence of chronic kidney disease (CKD) in the Chinese adult population of $10.8 \%$ and the Chinese National Renal Data System showed that there were $>670,000$ patients receiving

Zhuo Li and Guibao Ke contributed equally to this work as first authors.
C 2021 The Author(s).

Published by S. Karger AG, Basel

This is an Open Access article licensed under the Creative Commons Attribution-NonCommercial-4.0 International License (CC BY-NC) (http://www.karger.com/Services/OpenAccessLicense), applicable to the online version of the article only. Usage and distribution for commercial purposes requires written permission.
Correspondence to:

Shuangxin Liu, 13543456446@163.com

Xinling Liang, xinlingliang_ggh@163.com 
uremic maintenance dialysis at the end of 2018. As of 2020, data from the United States Renal Data System revealed that about $15 \%$ of people in the USA had CKD, and the prevalence of end-stage renal disease in the USA remains one of the highest in the world, with 2,242 cases per million population in 2018 [1]. The incidences of atherosclerotic heart disease, myocardial infarction, and left ventricular hypertrophy (LVH) have increased significantly in patients with CKD, and the cardiovascular mortality of dialysis patients has increased 10-30 times compared with the general population [2]. More than $50 \%$ of deaths among hemodialysis (HD) patients are attributed to cardiovascular disease $[3,4]$. The main features of uremic cardiomyopathy are myocardial hypertrophy and fibrosis [5], which persist in both CKD patients and animal models $[6,7]$. LVH is a predictive marker of cardiovascular death [8]. Even after correcting for hypertension and anemia, left ventricular mass still increased in one-third of patients. Cardiac fibrosis also increases with time in HD patients and resolves with time after successful kidney transplantation [9]. The above data suggest that traditional dialysis methods cannot remove certain toxins, which may have high protein-binding properties and may thus play an important role in the progression of cardiovascular disease in CKD. Indoxyl sulfate (IS) is a representative protein-bound uremic toxin [10], which is mainly distributed in the kidneys, followed by the lungs, heart, and liver. IS cannot be effectively eliminated in patients with renal insufficiency, resulting in its accumulation in the body and harmful effects on various organs $[11,12]$. Previous studies showed that IS was closely related to mortality among dialysis patients $[12,13]$. The main aim of this study was to analyze the factors affecting serum IS concentrations in patients receiving maintenance $\mathrm{HD}(\mathrm{MHD})$, to provide valuable information for future studies.

\section{Methods}

\section{Subjects}

We enrolled 100 patients undergoing MHD in the blood purification center of Guangdong Provincial People's Hospital in December 2019. The inclusion criteria were (i) age $\geq 18$ years, (ii) regular HD (dialysis for $>12$ weeks, 3 times per week), and (iii) complete clinical data. The exclusion criteria were (i) malignant tumor, (ii) history of bleeding and blood transfusion in the past 3 months, and (iii) pregnancy. The study was conducted in accordance with the Declaration of Helsinki (as revised in 2013) and was approved by the Ethics Committee of Guangdong Provincial People's Hospital (No. GDREC2018344H). Written informed consent was obtained from all patients.

\section{Collection of Clinical Data}

We collected information on total-form IS levels, biochemical indicators, electrocardiograms, and echocardiography-related data during the same period. The main indicators included IS, left ventricular wall thickness, parathyroid hormone, and $\beta 2$ microglobulin. Secondary indicators included age, duration of $\mathrm{HD}$, sex, primary disease, electrocardiogram, hemoglobin, and other biochemical indicators.

\section{Statistical Analysis}

Quantitative data were analyzed using the Shapiro-Wilk test to determine the normality of the data. In this study, the IS value did not conform to a normal distribution and was therefore expressed as the median (25\%-75\% percentile), and values were compared between groups using nonparametric tests. Qualitative data were expressed as number of cases (\%) and compared between groups using $\chi^{2}$ or Fisher's tests. Correlations were analyzed using Spearman's correlation test. A variation inflation factor (VIF) $>10$ was considered to show serious multicollinearity between independent variables, in which case the more clinically important significant independent variable was used in the multiple linear regression model. Multiple linear regression analysis was used to explore the potential factors related to serum IS levels in patients with MHD. The two-way stepwise method was used to screen important influencing factors that were significantly related to serum IS values. A two-sided $p$ value $<0.05$ was considered to be statistically significant. The data were analyzed using $\mathrm{R}$ software (version 3.5.0, Vienna, Austria. Copyright c 1999-2018 R Core Team).

\section{Results}

\section{Patient Characteristics}

One hundred MHD patients were included in this study, according to the inclusion and exclusion criteria. The patients' demographics and clinical and biochemical data are shown in Table 1 . The average IS level was significantly higher in men than in women $(p<0.001)$. Using a cut-off age of 60 years ( $<60$ and $\geq 60$ years), the IS level was significantly lower in patients aged $<60$ compared with those $\geq 60$ years $(p=0.023)$. All patients completed echocardiography tests and patients with mitral regurgitation had significantly higher IS levels than those without mitral regurgitation $(p=0.047)$. The single-pool urea kinetic model $(\mathrm{KT} / \mathrm{V})$ is currently used as an indicator of dialysis adequacy, with a $\mathrm{KT} / \mathrm{V} \geq 1.2$ considered to indicate adequate dialysis. The current results suggested that IS levels were significantly lower in patients with adequate dialysis compared with the insufficient dialysis group $(p=0.008)$.

\section{Correlation Analysis}

In the correlation analysis (Fig. 1), a VIF $>10$ indicated the occurrence of serious multicollinearity between independent variables. The correlation coefficient between 
Table 1. Serum total-form IS levels in relation to sex, age, duration of HD, diabetes, echocardiography, electrocardiogram, and laboratory results in MHD patients

\begin{tabular}{|c|c|c|c|c|}
\hline Factor & Group & $N(\%)$ & IS value median [IQR] & $p$ value \\
\hline Sex & $\begin{array}{l}\text { Male } \\
\text { Female }\end{array}$ & $\begin{array}{l}50(50.0) \\
50(50.0)\end{array}$ & $\begin{array}{l}40.20[28.07,54.53] \\
27.73[19.25,32.67]\end{array}$ & $<0.001$ \\
\hline Age, years & $\begin{array}{l}<60 \\
\geq 60\end{array}$ & $\begin{array}{l}55(55.0) \\
45(45.0)\end{array}$ & $\begin{array}{l}28.29[23.27,40.20] \\
32.22[27.85,47.39]\end{array}$ & 0.023 \\
\hline Duration of HD, years & $\begin{array}{l}<1 \\
1-2 \\
2-3 \\
\geq 3\end{array}$ & $\begin{array}{l}23(23.0) \\
27(27.0) \\
16(16.0) \\
34(34.0)\end{array}$ & $\begin{array}{l}31.01[25.82,43.19] \\
30.81[24.54,37.89] \\
33.79[26.78,48.59] \\
29.02[21.44,42.44]\end{array}$ & 0.443 \\
\hline Urine volume, $\mathrm{mL} /$ day & $\begin{array}{l}<100 \\
100-400 \\
>400\end{array}$ & $\begin{array}{l}62(62.0) \\
15(15.0) \\
23(23.0)\end{array}$ & $\begin{array}{l}29.34[18.37,42.44] \\
26.04[16.59,35.19] \\
31.35[25.91,39.36]\end{array}$ & 0.365 \\
\hline Diabetes & $\begin{array}{l}\text { No } \\
\text { Yes }\end{array}$ & $\begin{array}{l}70(70.0) \\
30(30.0)\end{array}$ & $\begin{array}{l}30.26[25.00,41.70] \\
31.33[25.04,47.69]\end{array}$ & 0.236 \\
\hline \multicolumn{5}{|l|}{ Echocardiography } \\
\hline Pulmonary hypertension & $\begin{array}{l}\text { No } \\
\text { Yes }\end{array}$ & $\begin{array}{l}85(85.0) \\
15(15.0)\end{array}$ & $\begin{array}{l}28.06[25.00,41.40] \\
30.32[18.12,32.95]\end{array}$ & 0.884 \\
\hline Mitral regurgitation & $\begin{array}{l}\text { No } \\
\text { Yes }\end{array}$ & $\begin{array}{l}68(68.0) \\
32(32.0)\end{array}$ & $\begin{array}{l}25.78[22.09,29.05] \\
31.69[24.62,42.72]\end{array}$ & 0.047 \\
\hline $\begin{array}{l}\text { Left ventricular diastolic } \\
\text { dysfunction }\end{array}$ & $\begin{array}{l}\text { No } \\
\text { Yes }\end{array}$ & $\begin{array}{l}73(73.0) \\
27(27.0)\end{array}$ & $\begin{array}{l}26.45[18.73,40.71] \\
30.32[25.62,40.39]\end{array}$ & 0.299 \\
\hline LV́H & $\begin{array}{l}\text { No } \\
\text { Yes }\end{array}$ & $\begin{array}{l}83(83.0) \\
17(17.0)\end{array}$ & $\begin{array}{l}27.66[25.20,42.01] \\
30.32[20.86,35.92]\end{array}$ & 0.904 \\
\hline $\begin{array}{l}\text { Ventricular septal } \\
\text { thickness, mm }\end{array}$ & $\begin{array}{l}<12 \\
\geq 12\end{array}$ & $\begin{array}{l}80(80.0) \\
20(20.0)\end{array}$ & $\begin{array}{l}27.04[25.26,38.30] \\
30.56[20.18,43.45]\end{array}$ & 0.488 \\
\hline \multicolumn{5}{|l|}{ Electrocardiogram } \\
\hline Atrioventricular block & $\begin{array}{l}\text { No } \\
\text { Yes }\end{array}$ & $\begin{array}{l}91(91.0) \\
9(9.0)\end{array}$ & $\begin{array}{l}30.35[24.83,43.31] \\
40.36[32.22,41.55]\end{array}$ & 0.699 \\
\hline Myocardial damage & $\begin{array}{l}\text { No } \\
\text { Yes }\end{array}$ & $\begin{array}{l}89(89.0) \\
11(11.0)\end{array}$ & $\begin{array}{l}30.81[24.95,42.79] \\
36.24[24.70,46.14]\end{array}$ & 0.733 \\
\hline \multicolumn{5}{|l|}{ Laboratory results } \\
\hline $\mathrm{KT} / \mathrm{V}$ & $\begin{array}{l}<1.2 \\
\geq 1.2\end{array}$ & $\begin{array}{l}21(21.0) \\
79(79.0)\end{array}$ & $\begin{array}{l}42.79[31.35,48.40] \\
29.83[23.01,40.75]\end{array}$ & 0.008 \\
\hline Hemoglobin, $g / L$ & $\begin{array}{l}<100 \\
100-120 \\
\geq 120\end{array}$ & $\begin{array}{l}30(30.0) \\
54(54.0) \\
16(16.0)\end{array}$ & $\begin{array}{l}29.06[25.99,35.61] \\
31.05[22.41,43.10] \\
38.42[25.72,43.77]\end{array}$ & 0.637 \\
\hline Albumin, g/L & $\begin{array}{l}<35 \\
35-40 \\
\geq 40\end{array}$ & $\begin{array}{l}23(23.0) \\
34(34.0) \\
43(43.0)\end{array}$ & $\begin{array}{l}31.01[25.88,32.59] \\
36.08[24.53,46.39] \\
28.86[24.95,31.92]\end{array}$ & 0.203 \\
\hline Phosphorus, mmol/L & $\begin{array}{l}<1.45 \\
1.45-2.00 \\
\geq 2.00\end{array}$ & $\begin{array}{l}20(20.0) \\
31(31.0) \\
49(49.0)\end{array}$ & $\begin{array}{l}29.06[23.94,43.89] \\
27.85[24.54,36.91] \\
31.66[25.37,44.15]\end{array}$ & 0.645 \\
\hline Parathormone, ng/L & $\begin{array}{l}<300 \\
300-500 \\
\geq 500\end{array}$ & $\begin{array}{l}53(53.0) \\
20(20.0) \\
27(27.0)\end{array}$ & $\begin{array}{l}31.35[25.85,42.79] \\
29.30[22.39,44.76] \\
30.32[20.09,40.20]\end{array}$ & 0.618 \\
\hline Uric acid, $\mu \mathrm{mol} / \mathrm{L}$ & $\begin{array}{l}<420 \\
\geq 420\end{array}$ & $\begin{array}{l}23(23.0) \\
77(77.0)\end{array}$ & $\begin{array}{l}31.10[26.20,46.07] \\
30.45[24.13,42.22]\end{array}$ & 0.526 \\
\hline$\beta 2$-microglobulin, mg/L & $\begin{array}{l}<20 \\
20-40 \\
\geq 40\end{array}$ & $\begin{array}{l}4(4.0) \\
90(90.0) \\
6(6.0)\end{array}$ & $\begin{array}{l}25.49[22.01,28.59] \\
31.05[24.82,42.73] \\
35.86[27.96,44.82]\end{array}$ & 0.413 \\
\hline
\end{tabular}

$\mathrm{IQR}$, interquartile range.
Indoxyl Sulfate Levels in Hemodialysis Patients 


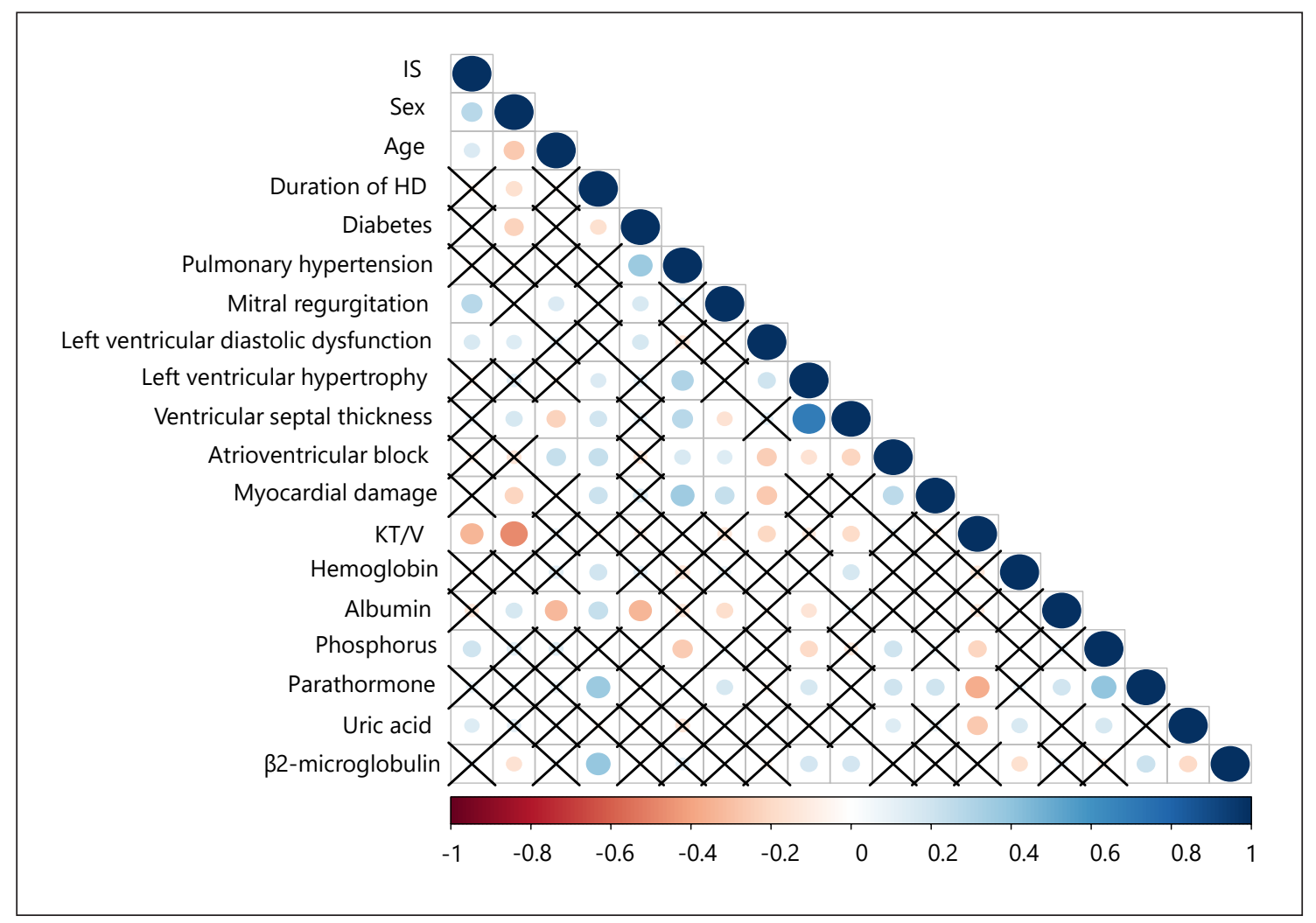

Fig. 1. Matrix correlation between potentially related factors and IS using Spearman's or Pearson's test. Positive and negative correlations indicated in blue and red, respectively. Color intensity and size of the circle are proportional to the correlation coefficient. " $x$ " means the correlation coefficient with $p>0.05$.

LVH and ventricular septal thickness was $>0.5$ and the VIF was $>10$. We therefore selected ventricular septum thickness as the more clinically significant independent variable for inclusion in the multiple linear regression model.

\section{Multiple Linear Regression Analysis of Serum IS}

\section{Levels in MHD Patients}

Multiple linear regression analysis showed that serum IS values were significantly correlated with sex and age in MHD patients ( $p=0.015$ and 0.002 , respectively) (Table 2). In addition, serum IS levels were significantly correlated with ventricular septal thickness and mitral regurgitation ( $p=0.006$ and 0.008 , respectively) (Table 2 ).

Serum IS Levels Differed between Sexes in HD Patients

We further explored differences in serum IS levels in dialysis patients according to age and sex. IS levels were significantly higher in male patients than in female patients in the same age group, regardless of whether they were younger or older than 60 years (Table 3 ).
Serum IS Levels in HD Patients with or without Mitral Regurgitation

Because serum IS levels were significantly correlated with mitral regurgitation, we further explored the differences in serum IS levels in dialysis patients with mitral regurgitation in relation to age and sex. IS levels in patients aged $\geq 60$ years were not related to the presence of mitral regurgitation, while patients aged $<60$ years with mitral regurgitation had significantly higher IS levels than patients without mitral regurgitation (Table 4).

\section{Discussion}

IS is a widely studied uremic solute, of which $>90 \%$ binds to plasma proteins [14]. The high clearance rate of IS is achieved through renal tubular secretion, which cannot be replaced by HD [15], and HD clearance is limited by protein binding because only free, unbound solutes can diffuse through the dialysis membrane [12]. Because of the lower dialysis clearance rate compared with the re- 
Table 2. Multiple linear regression analysis of serum total-form IS levels in MHD patients

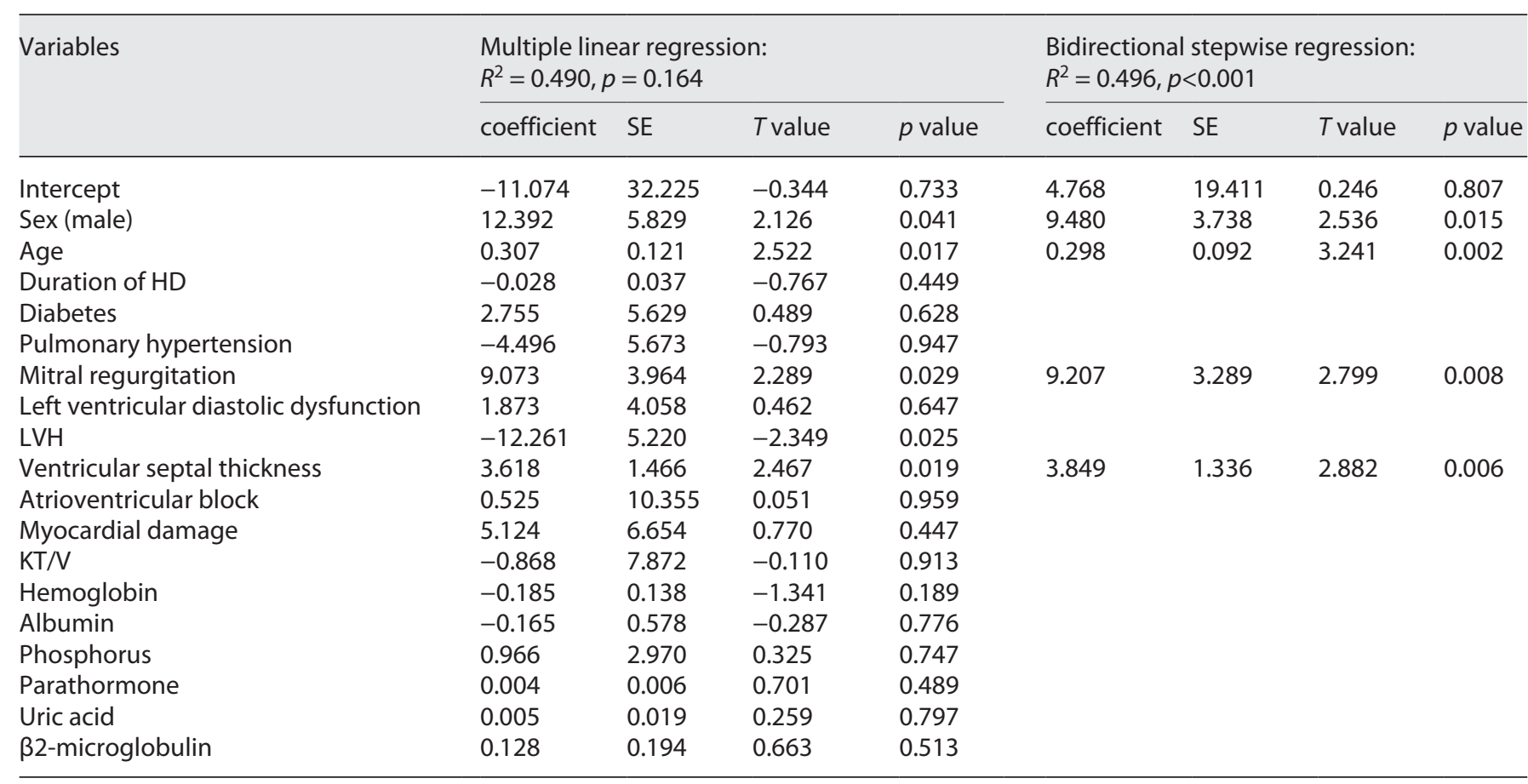

SE, standard error.

Table 3. Comparison of serum total-form IS levels in HD patients according to sex

\begin{tabular}{llllll}
\hline Sex & $\geq 60$ years & & & $<60$ years & \\
\cline { 2 - 3 } \cline { 5 - 6 } & cases, $n(\%)$ & IS value median [IQR] & & cases, $n(\%)$ & IS value median [IQR] \\
\hline Male & $21(46.7)$ & $44.98[31.10,58.65]$ & & $29(52.7)$ & $34.67[25.85,43.42]$ \\
Female & $24(53.3)$ & $31.24[23.31,38.27]$ & & $26(47.3)$ & $25.83[17.04,29.62]$ \\
\hline$p$ value & & 0.011 & & $<0.001$ \\
\hline
\end{tabular}

$\mathrm{IQR}$, interquartile range.

\begin{tabular}{|c|c|c|c|c|}
\hline \multirow{2}{*}{$\begin{array}{l}\text { Mitral } \\
\text { regurgitation }\end{array}$} & \multicolumn{2}{|l|}{$\geq 60$ years } & \multicolumn{2}{|l|}{$<60$ years } \\
\hline & cases, $n(\%)$ & IS value median [IQR] & cases, $n(\%)$ & IS value median [IQR] \\
\hline Yes & $16(35.6)$ & $31.69[20.18,42.21]$ & $16(29.1)$ & $31.88[25.95,43.44]$ \\
\hline No & $29(64.4)$ & $29.83[28.27,37.57]$ & 39 (70.9) & $25.26[18.78,25.83]$ \\
\hline$p$ value & & 0.934 & & 0.013 \\
\hline
\end{tabular}

IQR, interquartile range.
Table 4. Comparison of serum total-form IS levels in HD patients with or without mitral regurgitation serum IS levels were significantly increased in CKD patients $>60$ years of age, men, and patients with mitral regurgitation and inadequate dialysis. Furthermore, mul- 
tiple linear regression analysis identified sex, age, ventricular septal thickness, and mitral regurgitation as independent factors associated with serum IS.

IS is produced by the digestion of tryptophan by intestinal microorganisms, and its production increases with increased dietary protein intake [18]. According to the National Kidney Foundation K/DOQI Clinical Practice Guidelines for Nutrition in Chronic Renal Failure, individuals with different stages of CKD, energy intake, and dialysis modalities have different protein-intake requirements [19]. MHD patients require $1.2 \mathrm{~g} / \mathrm{kg} /$ day of protein, but the different body weights of men and women mean that the required standard amounts of protein intake differ, which may help to explain the significantly higher IS levels in male compared with female patients in this study. Several studies have shown the important role of residual renal function (RRF) in eliminating IS and the protein-bound solute p-cresol sulfate (PCS) in dialysis patients [20,21]; however, some inconsistencies remain. Lin et al. [22] showed that serum-free and total IS levels were similar in peritoneal dialysis patients with and without RRF; notably however, serum-free and total PCS levels were lower in patients with RRF than those without. Huang et al. [23] reported that free-form IS levels were lower in patients with RRF compared with anuric patients, while serum total-form IS levels were similar in the non-anuric and anuric groups. Pham et al. [24] also reported no difference in serum total-form PCS levels between non-anuric and anuric dialysis patients. Similarly, Bammens et al. [25] demonstrated that increasing PCS levels did not parallel the decline in RRF in 24 incident peritoneal dialysis patients. The current results were similar to those of Huang et al. [23] and Lin et al. [22], and showed that serum total-form IS levels were not related to urine volume in MHD patients. However, the small sample size, retrospective design, and changes in physiological functions of HD patients, combined with the complexity of kidney disease, mean that our conclusions need to be confirmed in further studies. The most commonly used clinical methods for removing protein-bound uremic toxins are currently dietary intervention $[26,27]$ and hemoperfusion [28-30], suggesting that these procedures may have more benefits in male than in female dialysis patients.

Sudden cardiac death, heart failure, and ischemic heart disease are the three most common causes of cardiovascular death in CKD patients [2,31]. LVH, as a characteristic lesion of uremic cardiomyopathy, has become a predictive marker of cardiovascular death $[2,8,31]$. LVH refers to the pathological increase in the mass of the left ventricle and the relative thickness of the left ventricular wall, and extensive data have shown that ventricular septal thickness is positively correlated with LVH [32]. The current correlation analysis also suggested that LVH was positively correlated with ventricular septal thickness, consistent with the previous studies.

In the present study, the thickness of the ventricular septum in MHD patients was positively correlated with IS levels, suggesting that IS levels are closely related to the occurrence and severity of LVH. This may be due to the toxic effects of IS, such as leukocyte activation, changes in endothelial morphology and function, and stimulation of the interaction between endothelial cells and leukocytes, which can induce myocardial fibrosis and myocardial remodeling and, ultimately, lead to CVD, heart failure, and other adverse effects [33-35]. IS demonstrated strong dose-dependent pro-fibrosis and hypertrophy-promoting effects in neonatal rats, while other protein-bound toxins such as PCS, $\mathrm{m}$-cresol, $\mathrm{m}$-cresol sulfate, and phenylacetic acid had little or no effect [36]. Reducing IS also prevented cardiac fibrosis in the 5/6 nephrectomy model [37]. These data indicate the need for further studies to explore the potential of dietary intervention and hemoperfusion to improve IS-induced CVD and heart failure.

CKD is a major risk factor for valvular heart disease. Calcification of the mitral valve and aortic valve is very common in CKD patients, usually leading to valve stenosis and regurgitation. The 5-year mortality rate of patients with mild aortic stenosis or mitral regurgitation is $>50 \%$ higher than that in patients without CKD [38]. The current study found that IS levels in patients $>60$ years of age were not related to the occurrence of mitral regurgitation; however, this result may have been affected by the increased incidence of degenerative valvular disease in elderly patients. In contrast, mitral regurgitation was significantly and positively correlated with IS levels in dialysis patients $<60$ years of age, suggesting that increased IS levels may play a role in the process of mitral regurgitation. Calcification of the mitral valve is common and can cause annular and valvular thickening, which could in turn lead to mitral regurgitation [39]. Early reports found that many complex factors contributed to valve calcification in CKD, including hyperphosphatemia, calcium phosphate products, parathyroid hormone, and $\beta 2$ microglobulin, and recently published data found that increased circulating IS levels were associated with chronic inflammation and oxidative stress. Activation of proinflammatory cytokines, together with the excessive production of reactive oxygen species, causes structural and electrical cardiac remodeling [40]. In addition, IS directly 
promoted vascular calcification in a CKD rat model via activation of coagulation, inflammation, and glucometabolic signaling pathways [41]. IS also promoted vascular calcification in cultured vascular smooth muscle cells and $5 / 6$ nephrectomy rats by increasing methylation of the a-klotho gene and subsequent transcriptional inhibition [42]. Dietary intervention and regular hemoperfusion may, thus reduce the incidence of mitral regurgitation in dialysis patients $<60$ years of age.

\section{Limitations}

This study had some limitations. First, the existing data were collected retrospectively from medical records, and some variables were thus inevitably missing. Fortunately, however, most of the required information for this study was included in the medical records. Second, the retrospective design may have led to selection and treatment biases. Third, the study population was Chinese, and the small sample size meant that race and ethnicity were not included as variables in the multiple linear regression analysis. Fourth, this study did not collect data on changes in the gut microbiota in HD patients, which might be relevant given that CKD-related dysbiosis is characterized by the prevalence of proteolytic species, and changes might reduce the clearance and increase the production of uremic toxins such as IS.

\section{Conclusions}

Male sex, age $\geq 60$ years, ventricular septal thickness, and mitral regurgitation are all associated with high total serum IS concentrations in Chinese HD patients. Elevated IS levels may play a role in the process of mitral regurgitation in HD patients under 60 years of age. Further multicenter, prospective trials are needed to confirm the current conclusions.

\section{Acknowledgment}

The authors acknowledge the support and assistance of the blood purification center of Guangdong Provincial People's Hospital for performing the study.

\section{Statement of Ethics}

The study protocol and consent form were approved by the Institutional Ethics Boards of Guangdong Provincial People's Hospital (No. GDREC2018344H), and written informed consent was obtained from all subjects prior to enrollment and participation.

\section{Conflict of Interest Statement}

The authors have no conflicts of interest to declare.

\section{Funding Sources}

This study was supported by the National Natural Science Foundation (No. 81670656, 81870508, and 81970625), Guangdong Province High-Level Hospital Construction Project (No. DFJH201901), Guangdong Provincial Science Foundation (No. 2019A1515010286), and Sichuan Science and Technology Program (2021YFS0159).

\section{Author Contributions}

Design of the study: Z.L., G.K., L.S., J.X., and Y.Z.; data acquisition: Z.L., S.L., and J.H.; data analysis: L.S., J.X., X.L., and J.H.; draft of the manuscript: G.K. and S.L.; manuscript revision and final version approval: S.L. and X.L. All authors have read and approved the final manuscript.

\section{Data Availability Statement}

All data generated or analyzed during this study are included in this article. Further inquiries can be directed to the corresponding author.

\section{References}

1 Johansen KL, Chertow GM, Foley RN, Gilbertson DT, Herzog CA, Ishani A, et al. US renal data system 2020 annual data report: epidemiology of kidney disease in the United States. Am J Kidney Dis. 2021 Apr;77(4 Suppl 1):A7-8.

2 Sarnak MJ, Levey AS, Schoolwerth AC, Coresh J, Culleton B, Hamm LL, et al. Kidney disease as a risk factor for development of cardiovascular disease: a statement from the American Heart Association Councils on kidney in cardiovascular disease, high blood pressure research, clinical cardiology, and epidemiology and prevention. Hypertension. 2003 Nov;42(5):1050-65.

3 Collins AJ, Foley RN, Chavers B, Gilbertson D, Herzog C, Johansen K, et al. United States renal data system 2011 annual data report: atlas of chronic kidney disease \& endstage renal disease in the United States. Am J Kidney Dis. 2012 Jan;59(1 Suppl 1):A7, e1420.

4 Tan Z, Ke G, Huang J, Yang D, Pi M, Li L, et al. Effects of carvedilol on cardiovascular events and mortality in hemodialysis patients, a systematic review and meta-analysis. Iran J Kidney Dis. 2020 Jul;14(4):256-66.

5 Garikapati K, Goh D, Khanna S, Echampati K. Uraemic cardiomyopathy: a review of current literature. Clin Med Insights Cardiol. 2021 Feb 23;15:1179546821998347.

6 Zhang AH, Guo WK, Yu L, Liu WH. Relationship of serum soluble klotho levels and echocardiographic parameters in patients on maintenance hemodialysis. Kidney Blood Press Res. 2019;44(3):396-404. 
7 Suassuna PGA, Cherem PM, de Castro BB, Maquigussa E, Cenedeze MA, Lovisi JCM, et al. aKlotho attenuates cardiac hypertrophy and increases myocardial fibroblast growth factor 21 expression in uremic rats. Exp Biol Med. 2020 Jan;245(1):66-78.

8 Peters MN, Seliger SL, Christenson RH, Hong-Zohlman SN, Daniels LB, Lima JAC, et al. "Malignant $\bigotimes$ left ventricular hypertrophy identifies subjects at high risk for progression to asymptomatic left ventricular dysfunction, heart failure, and death: MESA (Multi-Ethnic Study of Atherosclerosis). J Am Heart Assoc. 2018 Feb 8;7(4):e006619.

9 Contti MM, Barbosa MF, Del Carmen Villanueva Mauricio A, Nga HS, Valiatti MF, Takase HM, et al. Kidney transplantation is associated with reduced myocardial fibrosis. A cardiovascular magnetic resonance study with native T1 mapping. J Cardiovasc Magn Reson. 2019 Mar 27;21(1):21.

10 Duranton F, Cohen G, De Smet R, Rodriguez M, Jankowski J, Vanholder R, et al. Normal and pathologic concentrations of uremic toxins. J Am Soc Nephrol. 2012 Jul;23(7):125870.

11 Itoh Y, Ezawa A, Kikuchi K, Tsuruta Y, Niwa T. Protein-bound uremic toxins in hemodialysis patients measured by liquid chromatography/tandem mass spectrometry and their effects on endothelial ROS production. Anal Bioanal Chem. 2012 Jun;403(7):1841-50.

12 Yamamoto S, Fuller DS, Komaba H, Nomura T, Massy ZA, Bieber B, et al. Serum total indoxyl sulfate and clinical outcomes in hemodialysis patients: results from the Japan Dialysis Outcomes and Practice Patterns Study. Clin Kidney J. 2021 Apr;14(4):1236-43.

13 Barreto FC, Barreto DV, Liabeuf S, Meert N, Glorieux G, Temmar M, et al. Serum indoxyl sulfate is associated with vascular disease and mortality in chronic kidney disease patients. Clin J Am Soc Nephrol. 2009 Oct;4(10):15518.

14 Leong SC, Sirich TL. Indoxyl sulfate-review of toxicity and therapeutic strategies. Toxins. 2016 Nov 30;8(12):358.

15 Lowenstein J, Nigam SK. Uremic toxins in organ crosstalk. Front Med. 2021;8:592602.

16 Shafi T, Sirich TL, Meyer TW, Hostetter TH, Plummer NS, Hwang S, et al. Results of the HEMO Study suggest that $\mathrm{p}$-cresol sulfate and indoxyl sulfate are not associated with cardiovascular outcomes. Kidney Int. 2017 Dec; 92(6):1484-92.

17 Dias GF, Bonan NB, Steiner TM, Tozoni SS, Rodrigues S, Nakao LS, et al. Indoxyl sulfate, a uremic toxin, stimulates reactive oxygen species production and erythrocyte cell death supposedly by an organic anion transporter 2 (OAT2) and NADPH oxidase activity-dependent pathways. Toxins. 2018 Jul 5;10(7):280.

18 Tsai MH, Chang CH, Liou HH, Fang YW. Inverted $\mathrm{U}$-curve association between serum in- doxyl sulfate levels and cardiovascular events in patients on chronic hemodialysis. J Clin Med. 2021 Feb 13;10(4):744.

19 Kopple JD. National kidney foundation K/ DOQI clinical practice guidelines for nutrition in chronic renal failure. Am J Kidney Dis. 2001 Jan;37(1 Suppl 2):S66-70.

20 Viaene L, Meijers BK, Bammens B, Vanrenterghem Y, Evenepoel P. Serum concentrations of p-cresyl sulfate and indoxyl sulfate, but not inflammatory markers, increase in incident peritoneal dialysis patients in parallel with loss of residual renal function. Perit Dial Int. 2014 Jan-Feb;34(1):71-8.

21 Xie T, Bao M, Zhang P, Jiao X, Zou J, Ding X, et al. Serum concentration of indoxyl sulfate in peritoneal dialysis patients and low-flux hemodialysis patients. Blood Purif. 2019; 48(2):183-90

22 Lin CJ, Pan CF, Chuang CK, Liu HL, Sun FJ, Wang TJ, et al. Gastrointestinal-related uremic toxins in peritoneal dialysis: a pilot study with a 5-year follow-up. Arch Med Res. 2013 Oct;44(7):535-41.

23 Huang WH, Hung CC, Yang CW, Huang JY. High correlation between clearance of renal protein-bound uremic toxins (indoxyl sulfate and p-cresyl sulfate) and renal water-soluble toxins in peritoneal dialysis patients. Ther Apher Dial. 2012 Aug;16(4):361-7.

24 Pham NM, Recht NS, Hostetter TH, Meyer TW. Removal of the protein-bound solutes indican and $\mathrm{p}$-cresol sulfate by peritoneal dialysis. Clin J Am Soc Nephrol. 2008 Jan;3(1): 85-90.

25 Bammens B, Evenepoel P, Verbeke K, Vanrenterghem Y. Time profiles of peritoneal and renal clearances of different uremic solutes in incident peritoneal dialysis patients. Am J Kidney Dis. 2005 Sep;46(3):512-9.

26 Marzocco S, Dal Piaz F, Di Micco L, Torraca $S$, Sirico ML, Tartaglia D, et al. Very low protein diet reduces indoxyl sulfate levels in chronic kidney disease. Blood Purif. 2013; 35(1-3):196-201.

27 Yang HL, Feng P, Xu Y, Hou YY, Ojo O, Wang XH. The role of dietary fiber supplementation in regulating uremic toxins in patients with chronic kidney disease: a metaanalysis of randomized controlled trials. J Ren Nutr. 2021 Sep;31(5):438-47.

28 Yamamoto S, Sato M, Sato Y, Wakamatsu T, Takahashi Y, Iguchi A, et al. Adsorption of protein-bound uremic toxins through direct hemoperfusion with hexadecyl-immobilized cellulose beads in patients undergoing hemodialysis. Artif Organs. 2018 Jan;42(1):88-93.

29 Yamamoto S, Ito T, Sato M, Goto S, Kazama JJ, Gejyo F, et al. Adsorption of proteinbound uremic toxins using activated carbon through direct hemoperfusion in vitro. Blood Purif. 2019;48(3):215-22.

30 Magnani S, Atti M. Uremic toxins and blood purification: a review of current evidence and future perspectives. Toxins. 2021 Mar 30; 13(4):246.

31 Gross ML, Ritz E. Hypertrophy and fibrosis in the cardiomyopathy of uremia: beyond coronary heart disease. Semin Dial. 2008 Jul-Aug; 21(4):308-18.

32 Ivanov AP, Săeda EA, El'gardt IA, Sdobniakova NS. Importance of detection of hypertensive reaction to physical loading in patients with or without left ventricular hypertrophy and arterial hypertension. Klin Med. 2009;87(7):24-6.

33 Adijiang A, Goto S, Uramoto S, Nishijima F, Niwa T. Indoxyl sulphate promotes aortic calcification with expression of osteoblast-specific proteins in hypertensive rats. Nephrol Dial Transplant. 2008 Jun;23(6):1892-901.

34 Yamamoto S, Zuo Y, Ma J, Yancey PG, Hunley TE, Motojima M, et al. Oral activated charcoal adsorbent (AST-120) ameliorates extent and instability of atherosclerosis accelerated by kidney disease in apolipoprotein E-deficient mice. Nephrol Dial Transplant. 2011 Aug;26(8):2491-7.

35 Chen J, Zhang X, Zhang H, Liu T, Zhang H, Teng J, et al. Indoxyl sulfate enhance the hypermethylation of klotho and promote the process of vascular calcification in chronic kidney disease. Int J Biol Sci. 2016;12(10): 1236-46.

36 Lekawanvijit S, Kompa AR, Wang BH, Kelly DJ, Krum H. Cardiorenal syndrome: the emerging role of protein-bound uremic toxins. Circ Res. 2012 Nov 9;111(11):1470-83.

37 Fujii H, Nishijima F, Goto S, Sugano M, Yamato $\mathrm{H}$, Kitazawa R, et al. Oral charcoal adsorbent (AST-120) prevents progression of cardiac damage in chronic kidney disease through suppression of oxidative stress. Nephrol Dial Transplant. 2009 Jul;24(7): 2089-95.

38 Samad Z, Sivak JA, Phelan M, Schulte PJ, Patel U, Velazquez EJ. Prevalence and outcomes of left-sided valvular heart disease associated with chronic kidney disease. J Am Heart Assoc. 2017 Oct 11;6(10):e006044.

39 Straumann E, Meyer B, Misteli M, Blumberg A, Jenzer HR. Aortic and mitral valve disease in patients with end stage renal failure on long-term haemodialysis. Br Heart J. 1992 Mar;67(3):236-9.

40 Gao H, Liu S. Role of uremic toxin indoxyl sulfate in the progression of cardiovascular disease. Life Sci. 2017 Sep 15;185:23-9.

41 Opdebeeck B, Maudsley S, Azmi A, De Maré $A$, De Leger W, Meijers B, et al. Indoxyl sulfate and p-cresyl sulfate promote vascular calcification and associate with glucose intolerance. J Am Soc Nephrol. 2019 May;30(5):751-66.

42 Hénaut L, Chillon JM, Kamel S, Massy ZA. Updates on the mechanisms and the care of cardiovascular calcification in chronic kidney disease. Semin Nephrol. 2018 May;38(3): $233-50$. 